\title{
A case of neurofibromatosis with Chiari malformation type 1, syringobulbia and duplex system of the kidney
}

\author{
Sujeewa Amarasena ${ }^{1}$, L L Sudeva ${ }^{2}$, Ajith Hettigama ${ }^{3}$, Padmini Kolombage ${ }^{4}$
}

Sri Lanka Journal of Child Health, 2008; 37: 26-29

(Key words: neurofibromatosis, Chiari malformation, Syringobulbia, duplex kidney)

\section{Introduction}

Neurofibromatosis (NF) is a disorder with a wide spectrum of clinical manifestations. It is dominantly inherited with two main types. In type 1 (NF 1), the gene mutation is on the proximal long arm of chromosome 17 (17q11.2). Type II is a distinct disease both genetically (gene mutation on middle long arm of the chromosome 22) and clinically ${ }^{1,2}$. Six other types and a few variants have been described which do not fit into the 2 main types ${ }^{3}$. In NF 1 structural anatomical features include skin pigmentation, discrete plexiform neurofibromata and tumours of neuronal origin both in the central nervous system and peripheral nerves, ocular lesions, skeletal and other miscellaneous features ${ }^{1}$. The potential for functional impairment is massive with involvement of every possible body organ. It is important to be aware of the damage the disease could cause and to educate patients about this damage which may occur at different ages of life ${ }^{1}$.

\section{Case report}

A 10 year old girl was diagnosed to have NF 1. The diagnosis was based on plexiform neurofibromata over the right lumbar region and multiple café au lait spots (figure 1) at a very young age. She developed a urinary tract infection at the age of 4 years and was investigated. Ultrasound scan (USS) showed a large kidney on the right side suggestive of a duplex system. The duplex pelvis and upper ureters were later confirmed by intravenous pyelogram (figure 2). The left kidney was normal. Micturating cystourethrography did not show vesico ureteric reflux. Plexiform neurofibromata grew during follow-up. The parents requested intervention for cosmetic reasons and surgery was planned. The child

${ }^{1}$ Professor \& Head, Department of Paediatrics, Faculty of Medicine, Galle. ${ }^{2}$ Senior Registrar in Paediatrics, ${ }^{3}$ Registrar in Paediatrics, ${ }^{4}$ Consultant Radiologist, Teaching Hospital, Karapitiya.

(Received on 20 February 2007. Accepted on 20 March 2007)

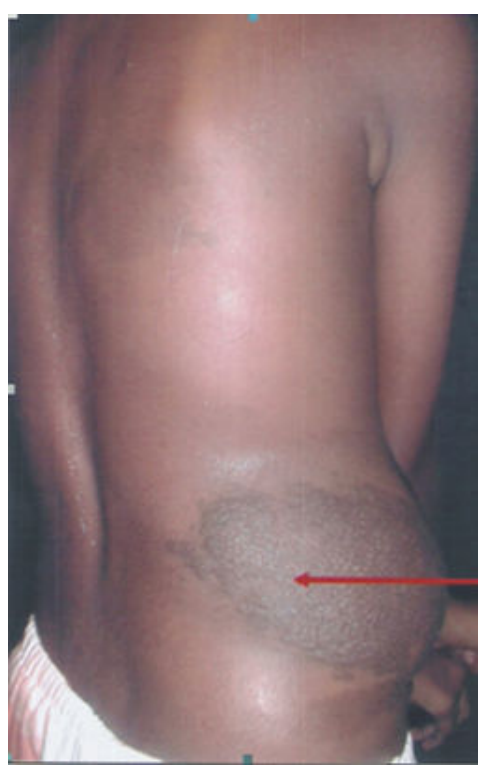

Figure 1 Plexiform neurofibroma with multiple caféau-lait patches

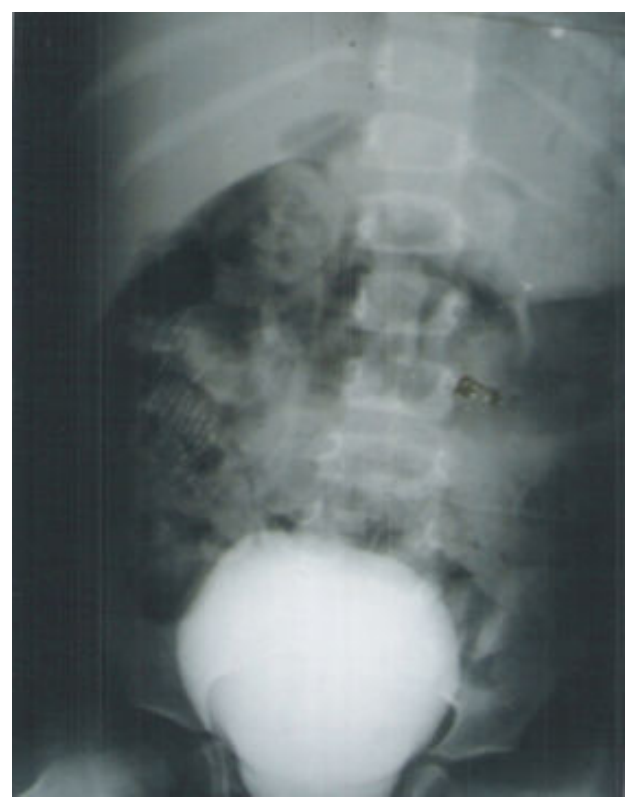

Figure 2 IVU shows incomplete duplex pelvicalyceal system on the right side 
was to be admitted on 26/12/2004 when the tsunami occurred. She lost all her medical records and found these in a pit close to her home. These notes were rewritten by a medical student from old blurred notes. Plastic surgery was being rearranged. She then developed scoliosis, Lisch nodules in the iris and backache. Magnetic resonance imaging (MRI) of the spine and brain was done. There was Chiari type 1 malformation (figure 3), syringobulbia (figure 4) and syringomyelia of almost the entire spinal cord down to the conus medullaris (figures $5 \& 6$ ). MRI also showed posterior scalloping of lumbar vertebrae with dural ectasia (figure 7).

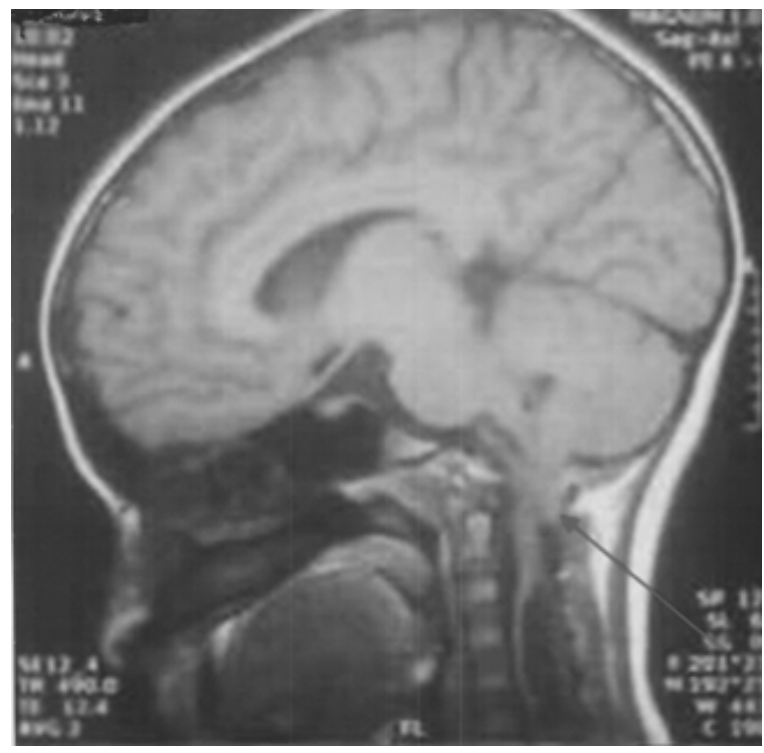

Figure 3 Arrow indicates tonsillar herniation

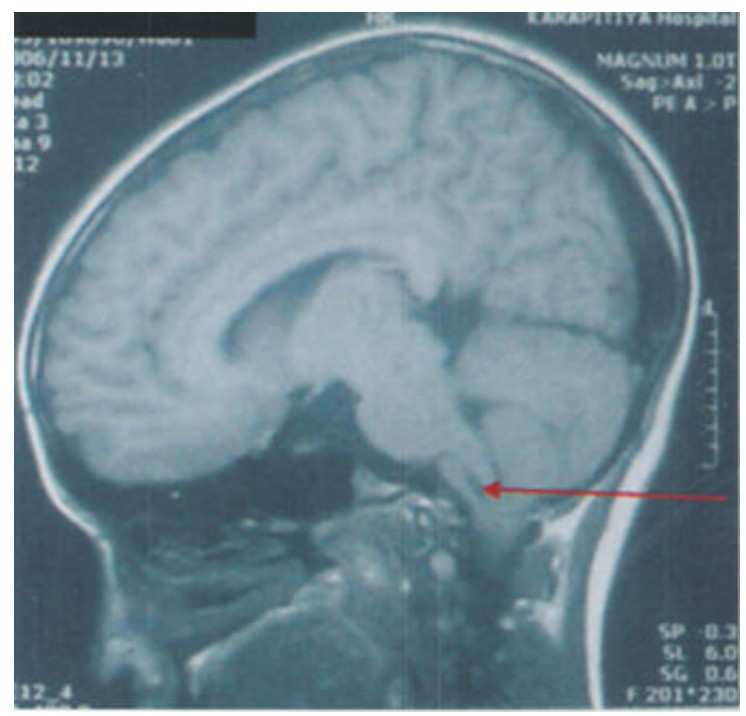

Figure 4 Arrow indicates syringobulbia

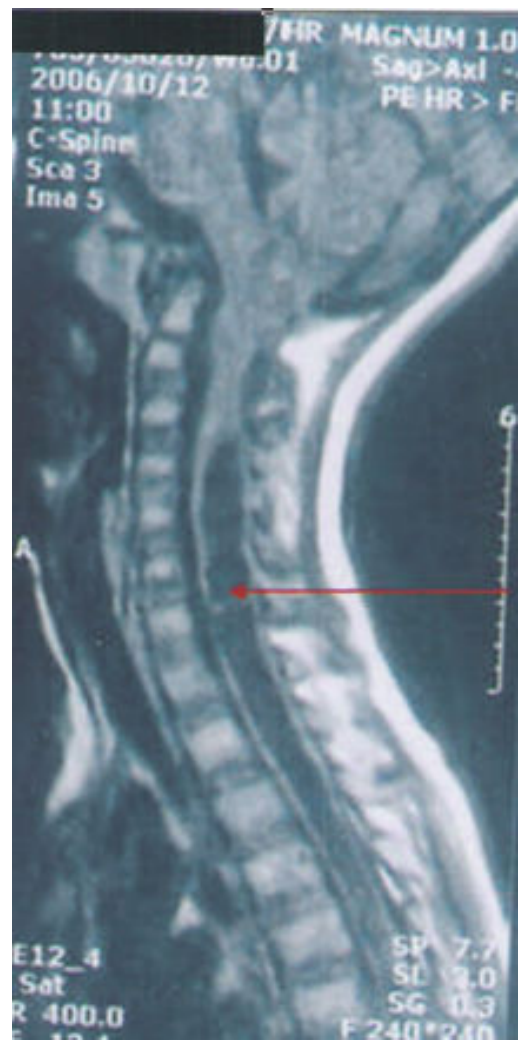

Figure 5 Cervical syringomyelia

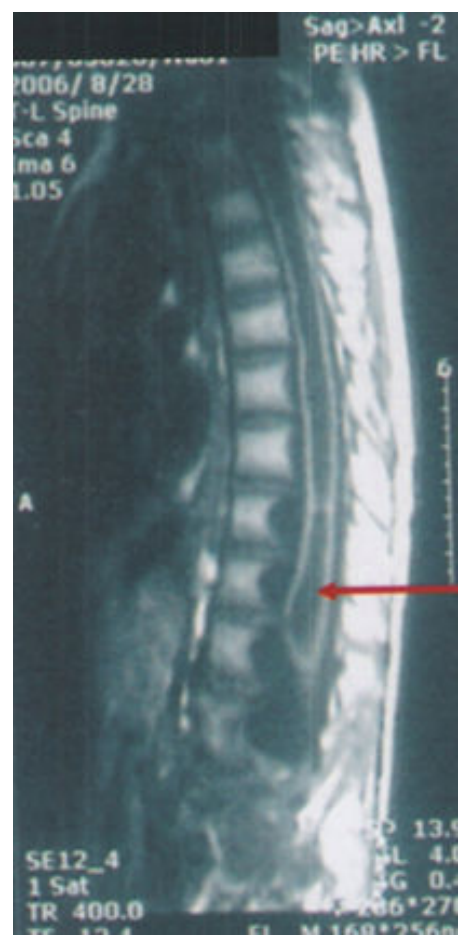

Figure 6 Lumbar syringomyelia 


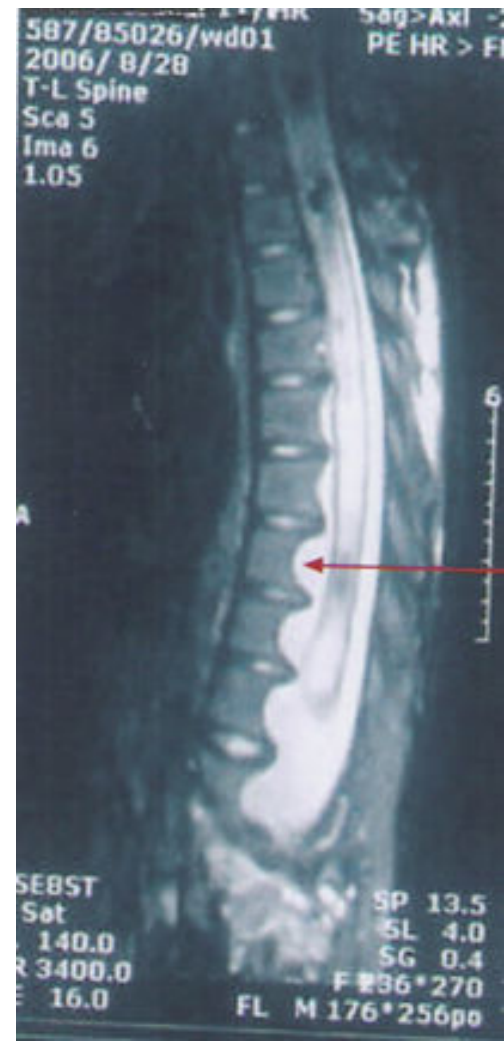

Figure 7 Posterior scalloping of lumbar vertebrae and dural ectasia

The child does not have symptoms or signs related to these abnormalities at present. There were no optic nerve gliomas, ventriculomegaly or other brain tumours. The child was referred for surgical intervention for the spinal lesion and is awaiting surgery. Her school performance had been suboptimal as she had been missing school regularly for medical and social reasons. There is no family history of the disease. Her longitudinal growth had been slow during follow up and her height was 130 $\mathrm{cm}$ at the age of 11 years $\left(1 \mathrm{~cm}<3^{\text {rd }}\right.$ centile). Head circumference was $54 \mathrm{~cm}$. Blood pressure (BP) was normal.

\section{Discussion}

Ventriculomegaly and Chiari type 1 malformation in NF 1 were first described by Afifi et al $^{4}$. The 2 cases had skeletal anomalies but no brain tumours to account for the ventriculomegaly. Subsequently 3 more cases were described with Chiari 1 malformation and ventriculomegaly ${ }^{5,6,7}$. The authors have argued that these are variants of NF. Chakrawarthy et al reported a case of optic pathway glioma, scoliosis, Chiari 1 malformation and syringomyelia as a variant of type $1^{8}$. All these reported cases are from the adult literature and it appears that development of ventriculomegaly occurs late in the disease, either during late teens or early twenties. This is also true in the case of syringomyelia and syringobulbia. Tubbs et al reported 7 cases of NF1 among 130 surgically addressed Chiari 1 malformation and 17 cases of Chiari 1 malformation among 198 patients with NF 1 in a retrospective analysis. Therefore it is a rare but true association with a late onset. The clinical features had been long known to appear at different age groups in patients with NF1 as congenital, infantile, late childhood, adolescent and adult ${ }^{1}$. Battistella $^{6}$ was the first to suggest that Chiari 1 should be added to the clinical spectrum of NF 1 . Clinicians may not be performing routine CT/MRI scans of the brain to identify this association early, although there is clear evidence that these investigations would help to identify the anomalies early $^{2}$. However, routine screening of children with $\mathrm{NF} 1$ for syringomyelia and Chiari 1 malformation around 10 years of age may detect the onset of these abnormalities early. It is not clear whether interventions are possible to relieve or prevent functional impairment, despite early identification.

The most common renal anomaly of NF 1 is renal artery stenosis and renovascular hypertension. The BP of this child was normal. She was not specifically investigated for renal artery stenosis. The finding of duplex kidney and duplex pelvi-calyceal system in this child is unusual and should raise the suspicion of this being another association of the disease. (We regret the poor quality of the photograph of this film which was damaged badly by the tsunami). Incidence of duplex ureters is 1 in 150 in the normal population and the incidence of NF 1 is 1 in $3000^{2}$. Therefore the chances of these 2 anomalies coexisting is extremely rare. A literature review found no such reported cases. One case report cannot be used to come to definitive conclusions. Routine screening of all children with NF 1 by USS may provide information. It is useful as many patients with NF 1 also develop intra abdominal neuronal tumours. By doing so, the timing of its onset can be identified in addition to the renal anomalies. The scoliosis of NF 1 is commonly due to involvement of the cervical and the upper thoracic vertebrae unlike this child where lumbar vertebrae were involved with dural ectasia. Dural ectasia is dilatation of the dural sac with posterior scalloping of vertebrae. This is well described in NF $1^{10}$.

Due to the heterogeneity of the disorder many workers have suggested including these as variants of type 1 or another type of NF. Genetic studies will 
help to classify variants into different types. We suggest Chiari malformation, syringomyelia and renal anomalies other than renal artery stenosis could be more common in NF 1 than clinicians appreciate. We believe these features are part of the spectrum of NF1.

\section{References}

1. McMillan JA, DeAngelis CD, Feigin RD, Warshaw JB, editors. Oski's Paediatrics. $3^{\text {rd }}$ ed. Philadelphia: Lippincott Williams \& Wilkins; 1999. p 2019-22.

2. Behrman RE, Kliegman RM, Jensen HB, editors. Nelson textbook of paediatrics. $17^{\text {th }}$ ed. Philadelphia: WB Saunders; 2004. p 1548-9, 2015-7.

3. Riccardi VM. Neurofibromatosis. Neurology Clinics 1987; 5: 337-49.

4. Afifi AK, Dolan KD, Van Gilder JC, et al. Ventriculomegaly in neurofibromatosis-1. Association of Chiari type 1 malformation. Neurofibromatosis 1988; 1: 299-305.

5. Dooley J, Vaughan D, Riding M, et al. The association of Chiari type 1 malformation and neurofibromatosis type 1 . Clinics Paediatrics Philadelphia 1993; 32: 189-90.
6. Battistella PA, Perilongo G, Catollo C. Neurofibromatosis type 1 and type 1 Chiari type 1 malformation: an unusual association. Child's Nervous System 1996; 12: 336-8.

7. Fernandez JA, Calleja PB, Paseual CI. Syringomyelia, Chiari 1 malformation and scoliosis in a patient with type 1 neurofibromatosis. An Esp Paediatric 1998; 48: 522-4.

8. Ckakrawarthy A. Bhargawa A, Nandy S. A patient with optic pathway glioma, scoliosis, Chiari 1 malformation and syringomyelia. Is it neurofibromatosis? Neurology India 2002; 50 (4): 520-1.

9. Tubbs RS, Rutledge SL, Kozantides A, Bartolucii AA, Oakes WJ. Chiari 1 malformations \& Neurofibromatosis type 1 . Paediatric Neurology 2004; 30 (4): 278-80.

10. Aicardi J, Bax M, Gillberg C, Ogier H, Alcardi J. Diseases of the nervous system in childhood. $2^{\text {nd }}$ ed. London: Cambridge University Press; 1998. p 131-6. 